\title{
Unusual ionospheric effects observed during the intense 28 October 2003 solar flare in the Brazilian sector
}

\author{
Y. Sahai ${ }^{1}$, F. Becker-Guedes ${ }^{1}$, P. R. Fagundes ${ }^{1}$, W. L. C. Lima ${ }^{2}$, A. J. de Abreu ${ }^{1}$, F. L. Guarnieri ${ }^{1}$, C. M. N. Candido ${ }^{3}$, \\ and V. G. Pillat ${ }^{1}$ \\ ${ }^{1}$ Universidade do Vale do Paraiba (UNIVAP), Sao Jose dos Campos, SP, Brazil \\ ${ }^{2}$ Centro Universitario Luterano de Palmas (CEULP/ULBRA), Palmas, TO, Brazil \\ ${ }^{3}$ Instituto Nacional de Pesquisas Espaciais (INPE), Sao Jose dos Campos, SP, Brazil
}

Received: 25 June 2007 - Revised: 26 September 2007 - Accepted: 23 October 2007 - Published: 2 January 2008

\begin{abstract}
The 28 October 2003 solar flare (X-ray Class $\mathrm{X} 17.2$ ) was one of the most intense solar flares observed in the recent past. In the present investigation we show the unusual ionospheric effects observed in the Brazilian sector during this solar flare, using both the ionospheric sounding observations obtained at the UNIVAP stations: Palmas (7-10.2 ${ }^{\circ} \mathrm{S}, 48.2^{\circ} \mathrm{W}$, dip lat. 5.5 $\mathrm{S}$ ) and Sao Jose dos Campos $\left(23.2^{\circ} \mathrm{S}, 45.9^{\circ} \mathrm{W}\right.$, dip lat. $\left.17.6^{\circ} \mathrm{S}\right)$, Brazil; and ground-based global positioning system (GPS) data obtained at the "Instituto Brasileiro de Geografia e Estatística" (IBGE) stations: Imperatriz $\left(5.5^{\circ} \mathrm{S}, 47.5^{\circ} \mathrm{W}\right.$, dip lat. $\left.2.9^{\circ} \mathrm{S}\right)$, Brasilia $\left(15.9^{\circ} \mathrm{S}, 47.9^{\circ} \mathrm{W}\right.$, dip lat. $\left.11.7^{\circ} \mathrm{S}\right)$, Presidente Prudente $\left(22.3^{\circ} \mathrm{S}, 51.4^{\circ} \mathrm{W}\right.$, dip lat. $\left.14.9^{\circ} \mathrm{S}\right)$, and Porto Alegre $\left(30.1^{\circ} \mathrm{S}, 51.1^{\circ} \mathrm{W}\right.$, dip lat. $\left.20.7^{\circ} \mathrm{S}\right)$, Brazil; on two consecutive days, viz., 27 (without solar flare) and 28 (with solar flare) October 2003. It should be mentioned that the vertical total electron content (VTEC) from the GPS observations obtained during the solar flare showed an unusual simultaneous increase in the VTEC values at about 11:00 UT at all four stations associated with the solar flare EUV enhancements and lasted for about $3 \mathrm{~h}$. However, no ionograms were obtained at any of the two UNIVAP stations for a period of about $1 \mathrm{~h}$ between about 11:00 to 12:00 UT. Before 11:00 UT (from about 10:45 UT) and after 12:00 UT (to about 16:00 UT), the ionograms were only partial, with the low frequency end missing. During this intense solar flare, hard X-rays (1 to 10 A), as observed by the GOES 12 satellite, were ejected by the Sun during a long period (several hours), with peak radiation at about 11:10 UT. These hard X-ray radiations can penetrate further into the ionosphere, causing an increase in ionization in the lower part of ionosphere (D-region). In this way, the lack of ionograms or partial ionograms, which indicates no echoes or partial echoes of the transmitted digital ionosonde signals, are related to intense absorption, resulting
\end{abstract}

Correspondence to: Y. Sahai

(sahai@univap.br) in complete or partial fade-out of radio signals at the lower ionospheric heights. The partial and complete radio fade-out observed in the Brazilian sector for more than six hours must have resulted in considerable difficulties to the radio station operating agencies using ionospheric radio transmissions.

Keywords. Ionosphere (Equatorial ionosphere, Ionosphere disturbance) - Solar astrophysics and astronomy (Flares and mass ejections)

\section{Introduction}

Schunk and Sojka (1996) have described in detail several ionosphere-thermosphere space weather issues and mentioned that weather disturbances in the ionospherethermosphere system can have a detrimental effect on both ground-based and space-based systems. Recent studies by Kelley et al. (2006) indicate that the most severe ionospheric weather occurs within $\pm 20^{\circ}$ of the geomagnetic equator where stored gravitational energy is sometimes released after sunset, depending on the condition of the equatorial ionosphere, to form vast plumes of turbulent plasma. Kelley et al. (2006) have termed this as convective ionospheric storms, to emphasize the analogy of the ionospheric process to thunderstorm. In this paper, we present another class of space weather event when, during a strong solar flare on 28 October 2003, for more than six hours, there were either no ionograms (1 to $20 \mathrm{Mhz}$ ) or only partial ionograms (high frequency end) obtained at two Brazilian ionospheric sounding stations viz., Palmas $\left(10.2^{\circ} \mathrm{S}, 48.2^{\circ} \mathrm{W}\right.$; hereafter referred to as PAL) and Sao Jose dos Campos $\left(23.2^{\circ} \mathrm{S}, 45.9^{\circ} \mathrm{W}\right.$; hereafter referred to as SJC). This indicates complete or partial fade-out of short-wave radio propagation through the ionospheric region in this sector. Needless to say that the radio fade-out for several hours must have resulted in enormous difficulties to several agencies and organizations associated

Published by Copernicus Publications on behalf of the European Geosciences Union. 


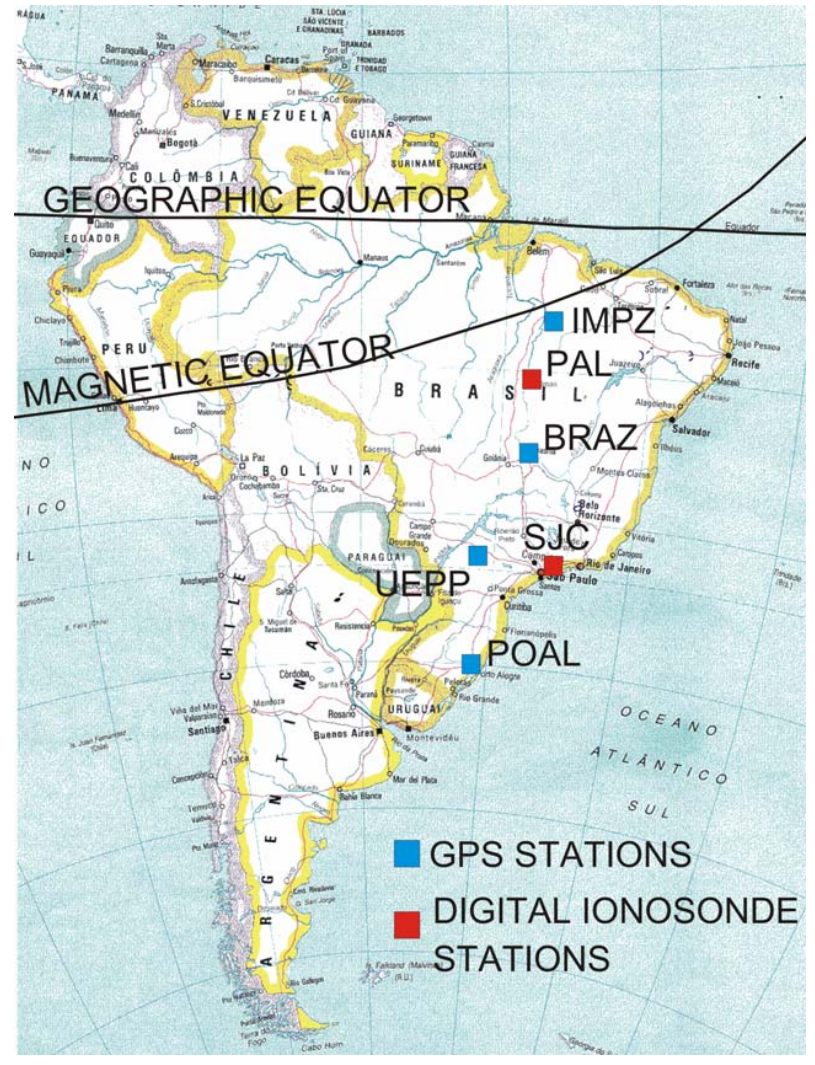

Fig. 1. Map of South America showing the locations of the ionospheric sounding (red marks) and GPS (blue marks) stations. In addition, the geographic and magnetic (based on IGRF-9, 2000) equators are shown.

with radio-communication and transmission of radio programs in this region.

The solar flare on 28 October 2003 was amongst the most intense (X17.2) recorded by the National Oceanic and Atmospheric Administration (NOAA), USA, in recent years. Using data from about 100 GPS receivers around the globe and the Global Ultraviolet Imager (GUVI) in the NASA TIMED satellite mission, Tsurutani et al. (2005) have analyzed this extreme EUV solar flare and resultant extreme ionospheric effects. It should be mentioned that Tsurutani et al. (2005) have observed an enhancement of about 25 TECU $\left(25 \times 10^{12}\right.$ electrons $\left./ \mathrm{cm}^{2}\right)$ for about $3 \mathrm{~h}$, in an extended area covering mostly Africa, Eastern South America and Central America, the region with overhead Sun, soon after the solar flare. It should be mentioned that a recent report (http://spaceflightnow.com/news/n0704/04gpssun) related to solar flare on 5 December 2006, indicates that GPS systems around the globe were significantly impacted by a powerful solar radio burst. In this paper we present, in addition to the ionospheric sounding observations from PAL and SJC, the complementary GPS data available from several stations in the Brazilian sector (Table 1) obtained by the "Rede Brasileira de Monitoramento Continuo de GPS (RBMC; Brazilian Network for Continuous GPS Monitoring)" run by the "Instituto Brasileiro de Geografia e Estatística (IBGE; Brazilian Institute of Geography and Statistics)", Brazil, on 27 and 28 October 2003.

\section{Solar flare radiations}

As mentioned by Papagiannis (1972), most of the sudden ionospheric disturbances (SIDs) are directly related to the ionization of the D-layer, which is the result of the X-ray burst from the solar flare. During quiet days, the D-region is maintained by the Lyman- $\alpha(121.6 \mathrm{~nm})$ emission from the Sun and by the galactic cosmic rays (lower D-region). The quiet Sun emits practically no X-rays below $1 \mathrm{~nm}$ and therefore all the solar X-rays are stopped above the D-region. The $\mathrm{X}$-ray emission from a flare, however, extends easily into the $0.1 \mathrm{~nm}$ range, which can reach the D-region and increase its electron density by at least one order of magnitude. Hargreaves (1992) points out that the nature and timing of the shortwave fadeout ( $S W F$ ) immediately provides two clues to its nature. The simultaneity between the fadeout and the visible flare (as seen in the red light of the Balmer- $\alpha$ line $(656.3 \mathrm{~nm}))$ shows that the cause is electromagnetic; and the occurrence of radio absorption indicates that the electron density in the D-region has been increased. Thus, the enhancement is most likely to be in the Lyman- $\alpha$ or the Xray flux. Lyman- $\alpha$ is enhanced by a few percent during a flare, and for many years this was thought to be the cause of the SWF. However, when it became possible to measure hard X-rays from rockets it was observed that they intensified by several powers of ten during a flare; thus, the SWF is now attributed to the X-rays from the flare. Davies (1990a) classified X-ray flares, in the wavelength range 1-8 A (0.1$0.8 \mathrm{~nm}$ ), as $C, M$, and $X$, depending on the power flux level, $\phi$.

$\begin{array}{ll}\text { Class } & \text { Peak flux }\left(\mathrm{W} \mathrm{m}^{-2}\right) \\ \mathrm{C} & 10^{-6} \leq \phi \leq 10^{-5} \\ \mathrm{M} & 10^{-5} \leq \phi \leq 10^{-4} \\ \mathrm{X} & 10^{-4} \leq \phi\end{array}$

Davies (1990b) points out that X-ray flares are increased emissions in the wavelength range 1-8 A. They are particularly important from the point of view of the ionospheric radio because these wavelengths ionize the D-region, which results in radio absorption. Most class- $X$ flares and some class-M flares produce short-wave fadeouts that affect radio communication. During solar flares extreme EUV radiation also show unusual enhancements (see Fig. 1 of Tsururatni et al., 2005). 
Table 1. Details of the global positioning system (GPS) and digital ionosonde (DI) sites in Brazil used in the present study. For all the stations $\mathrm{LT}=\mathrm{UT}-3 \mathrm{~h}$.

\begin{tabular}{|c|c|c|c|c|c|}
\hline Location & $\begin{array}{l}\text { Symbol used } \\
\text { (Network) }\end{array}$ & Observations & Geog. Lat. & Geog. Long. & Dip Lat. \\
\hline Imperatriz & $\begin{array}{l}\text { IMPZ } \\
\text { (RBMC) }\end{array}$ & GPS & $05.5^{\circ} \mathrm{S}$ & $47.5^{\circ} \mathrm{W}$ & $02.9^{\circ} \mathrm{S}$ \\
\hline Palmas & $\begin{array}{l}\text { PAL } \\
\text { (UNIVAP) }\end{array}$ & DI & $10.2^{\circ} \mathrm{S}$ & $48.2^{\circ} \mathrm{W}$ & $05.5^{\circ} \mathrm{S}$ \\
\hline Brasilia & $\begin{array}{l}\text { BRAZ } \\
\text { (RBMC) }\end{array}$ & GPS & $15.9^{\circ} \mathrm{S}$ & $47.9^{\circ} \mathrm{W}$ & $11.7^{\circ} \mathrm{S}$ \\
\hline $\begin{array}{l}\text { Presidente } \\
\text { Prudente }\end{array}$ & $\begin{array}{l}\text { UEPP } \\
\text { (RBMC) }\end{array}$ & GPS & $22.1^{\circ} \mathrm{S}$ & $51.4^{\circ} \mathrm{W}$ & $14.9^{\circ} \mathrm{S}$ \\
\hline $\begin{array}{l}\text { São José } \\
\text { dos Campos }\end{array}$ & SJC (UNIVAP) & DI & $23.2^{\circ} \mathrm{S}$ & $45.9^{\circ} \mathrm{W}$ & $17.6^{\circ} \mathrm{S}$ \\
\hline Porto Alegre & $\begin{array}{l}\text { POAL } \\
\text { (RBMC) }\end{array}$ & GPS & $30.1^{\circ} \mathrm{S}$ & $51.1^{\circ} \mathrm{W}$ & $20.7^{\circ} \mathrm{S}$ \\
\hline
\end{tabular}

\section{Observations}

In order to initiate the establishment of a new ionospheric sounding network in Brazil, a Canadian Advanced Digital Ionosonde (CADI) (Grant et al., 1995) was put in operation at SJC in August 2000 by the Universidade do Vale do Paraiba (UNIVAP). This was followed by the installation of two more CADIs at PAL and Manaus $\left(2.9^{\circ} \mathrm{S}, 60.0^{\circ} \mathrm{W}\right)$, in collaboration with the Universidade Luterana do Brasil (ULBRA). Due to some technical problems with the CADI at Manaus, only data from SJC and PAL are presented in this work. Details of the two ionospheric sounding stations (PAL and SJC) used in the present study are given in Table 1. It should be mentioned that PAL is a near-equatorial station, whereas SJC is located under the southern crest of the equatorial ionospheric anomaly. The two ionospheric sounding stations (PAL and SJC) have the same local time, with $\mathrm{UT}=\mathrm{LT}+3 \mathrm{~h}$. Figure 1 shows the locations of the two ionospheric soundings and four GPS stations used in the present investigations.

The CADI transmits frequencies from 1 to $20 \mathrm{MHz}$, with $600 \mathrm{~W}$ power, and the transmitted pulse has a length of $40 \mu \mathrm{s}$, which gives a $\pm 3 \mathrm{~km}$ height resolution. The antenna is a double delta dipole array supported by a 20 -m tower, where one of the dual antennas is used for transmitting, and the other one is used for receiving. The CADI operates in two different scanning modes. In the first mode it scans 180 frequencies every $300 \mathrm{~s}$, to provide a normal ionogram. In the second mode it scans only 6 frequencies $(3,4,5,6,7$ and $8 \mathrm{MHz}$ ), but with a higher temporal resolution (100 s). Using the software developed at the UNIVAP called UNIVAP DIGITAL IONOSONDE DATA ANALYSIS - UDIDA, it is possible to visualize ionograms on a PC screen and scale different ionospheric parameters. UDIDA also provides the daily height variations at the six fixed frequencies obtained in a

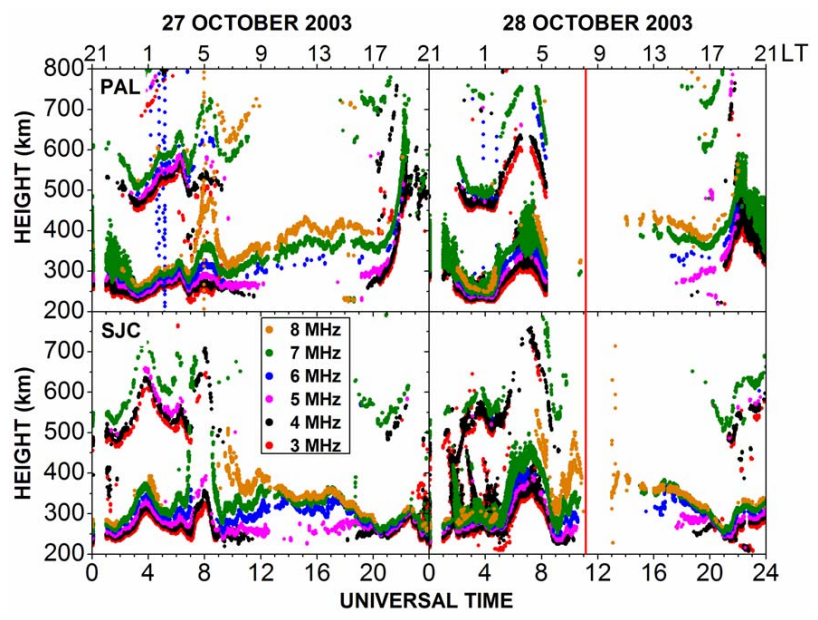

Fig. 2. Plots of virtual height variations for six different frequencies (iso-frequencies 3, 4, 5, 6, 7, and $8 \mathrm{MHz}$.) observed at PAL and SJC for the UT days 27 and 28 October 2003. The vertical red line indicates the peak in solar flare at 11:10 UT.

higher time resolution, known as iso-frequency plots. The iso-frequency plots from observations on UT days 27 (a normal day) and 28 October 2003 (solar flare day) at PAL and SJC are shown in Fig. 2. It should be mentioned that due to some technical problem, the CADI at PAL was not operational from about 08:20 UT to 10:40 UT on 28 October 2003 and it was just returning to provide normal ionograms when the solar flare resulted in a fade out.

The GPS data obtained at the four stations presented in Table 1 are used to obtain the vertical total electron content (VTEC) on UT days 27 and 28 October 2003 (Fig. 3). 


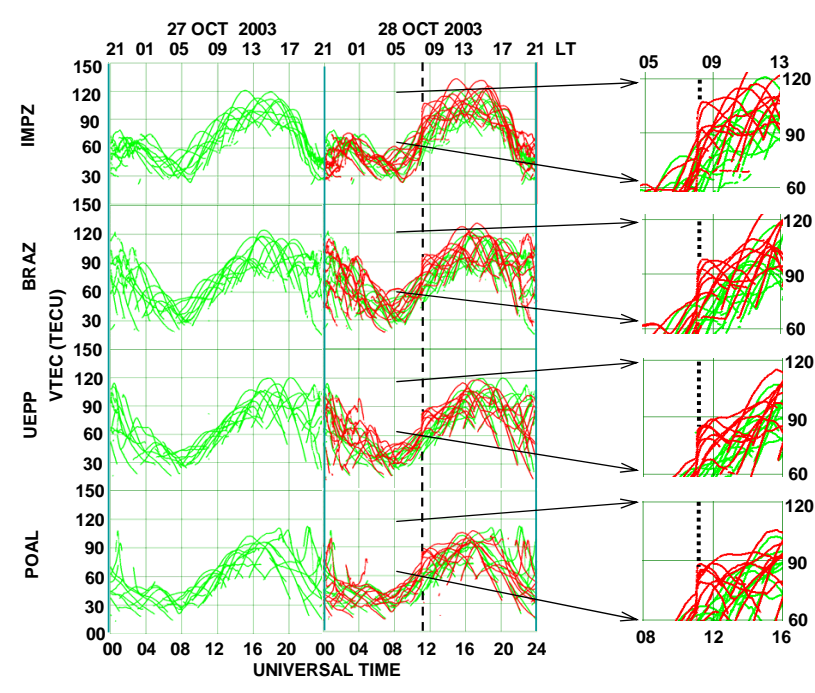

Fig. 3. Vertical total electron content (VTEC) observed at Imperatriz (IMPZ), Brasília (BRAZ), Presidente Prudente (UEPP), and Porto Alegre (POAL) stations (Table 1) on UT days 27 (green lines) and 28 (red lines) October 2003. A blowup of the VTEC data near the flare time is shown on the right-hand side.

\section{Results and discussion}

Mitra (1974) has published an excellent review on the ionospheric effects of solar flares. As discussed earlier and mentioned by Tsurutani et al. (2005), the impulsive ionization of the flare radiation causes enhanced ionization over a broad altitude range from the D-region ( $80-100 \mathrm{~km}$ altitude) all the way to the F-region (the F-region peak is at about the $300-\mathrm{km}$ altitude).

It should be mentioned that the sunspot group 486 was near the solar disc center on 28 October 2003 and unleashed a huge H-alpha 4B/X-17.2 class solar flare at about 11:00 UT (N. Srivastava, Udaipur Solar Observatory, India, private communication, 2004). Figure 3 shows the vertical total electron content observations at the four GPS stations (Table 1) on 27 October (a normal day) and 28 October (solar flare day). The observations on 27 October (green lines) are repeated on 28 October, as well, just for a comparative study. It is observed in Fig. 3 that soon after the solar flare on 28 October, all four stations show a sudden increase in the TEC levels (black dotted vertical line). A blowup of the VTEC data near the flare time in Fig. 3 indicates that the average TEC enhancements observed at the four stations are about 25 TECU and last for about $3 \mathrm{~h}$. The observations are very similar to that reported by Tsurutani et al. (2005). The TEC enhancements observed are due to the enhancements in the extreme EUV radiations associated with the intense solar flare (Tsurutani et al., 2005, Zhang and Xiao, 2005).

As mentioned earlier due to some technical problem, the ionospheric sounding at PAL stopped between 08:20 UT and 10:40 UT. The vertical red line in Fig. 2 shows the time of

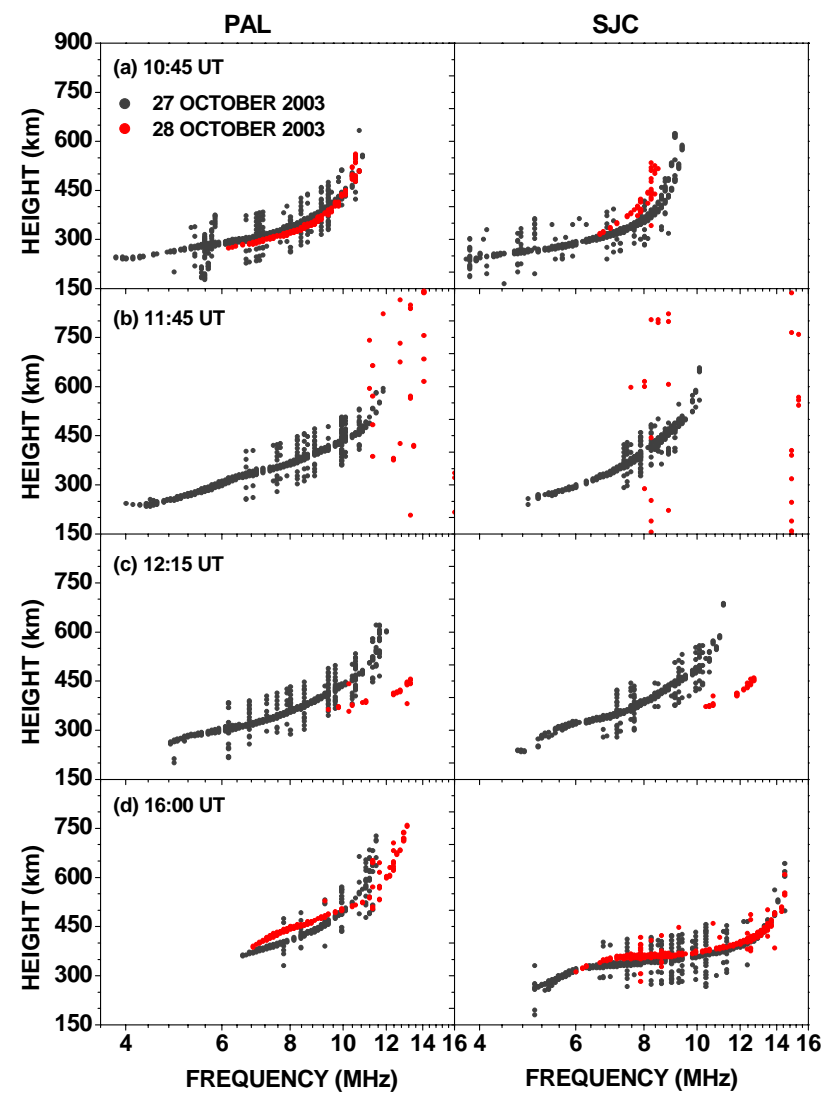

Fig. 4. The ionograms obtained at (a) 10:45 UT, (b) 11:45 UT, (c) 12:15 UT and (d) 16:00 UT on 27 October 2003 (normal day; black dots) and 28 October 2003 (solar flare day; red dots) at PAL and SJC. This period covers the ionograms obtained with partial radio wave absorption at 10:45, 12:15, and 16:00 UT and complete absorption at 11:45 UT.

the solar flare maximum (11:10 UT). It should be pointed out that to obtain the iso-frequencies plots the sounding frequencies are limited up to $8 \mathrm{MHz}$. Figure 2 shows that before the red vertical line there are increasing partial absorptions with lower frequencies at SJC. From 10:00 UT to 11:00 UT, only partial ionograms, with the lower frequency end missing, was observed at SJC. From 11:05 UT to 12:10 UT (sixtyfive minutes), no ionograms were observed at SJC. Again, from 12:15 UT to 16:40 UT, only partial ionograms, with the lower frequency end missing was observed at SJC. At PAL the ionospheric sounding started again at 10:45 UT, with partial ionograms up to 11:00 UT. From 11:05 UT to 11:50 UT (forty-five minutes) there were no ionograms observed at PAL. From 12:00 UT to 16:40 UT, only partial ionograms were observed at PAL. The complete ionograms at both stations were observed only at about 16:45 UT. Therefore, total + partial radio fade out lasted for more than $6 \mathrm{~h}$ (6h and $40 \mathrm{~min}$ ) in the Brazilian sector. Figure 4 shows four ionograms, each from both the stations, with ionograms observed on 28 October (red line; total + partial fade out) 


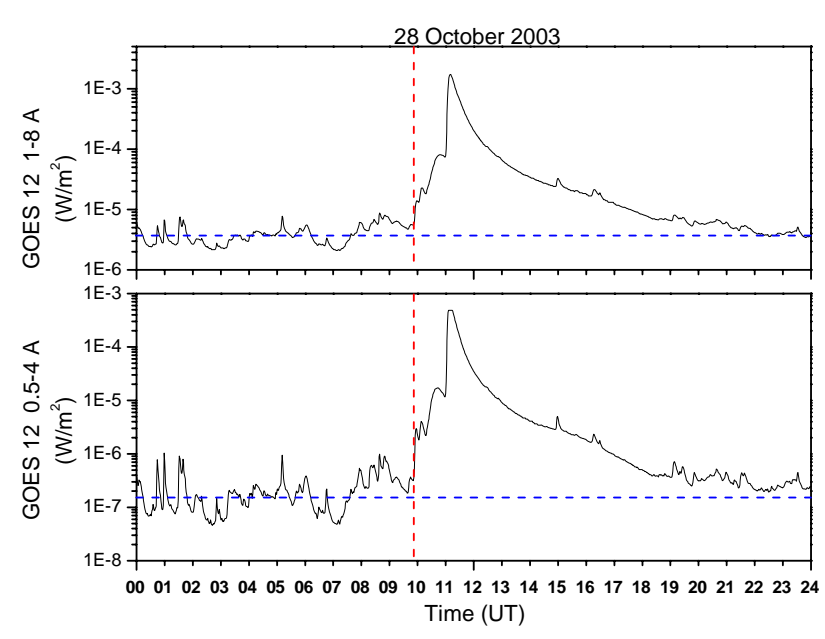

Fig. 5. Shows X-ray flux (1-8 A and $0.5-4 \mathrm{~A}$ ) observed on 28 October 2003 by the satellite GEOS 12 from 00:00 UT to 24:00 UT. The blue horizontal line indicates the quiescent X-ray flux. The red vertical lines indicates the onset of solar flare X-ray flux.

and 27 October (black; no fade out), for comparison. Figure 4 shows examples of partial radio wave absorption at 10:45, 12:15, and 16:00 UT and total radio wave absorption at 11:45 UT observed at PAL and SJC.

Figure 5 shows X-ray flux (1-8 A and $0.5-4 \mathrm{~A}$ ) observed on 28 October by the satellite GEOS 12 from 00:00 UT to 24:00 UT. A perusal of Fig. 5 indicates unusually large enhancements in both the bands (1-8 A and 0.5-4 A), starting at about 10:00 UT. As discussed earlier, the enhanced X-ray flux is responsible for an additional ionization in the D-layer, resulting in total + partial ionograms observed on 28 October in the Brazilian sector. The partial absorption of radio waves (frequencies $<9 \mathrm{MHz}$ ) is caused by a decrease in the signal intensity in the medium and short waves (see Fig. 3 in Mitra, 1974, p. 5).

Each GPS satellite, orbiting at an altitude of $20200 \mathrm{~km}$, transmits two carrier frequencies $(\mathrm{L} 1=1.57542 \mathrm{GHz}$ and $\mathrm{L} 2=1.22760 \mathrm{GHz}$; ultra high frequency) and TEC is indicative of the total electrons in the path between the satellite and a ground receiver. Therefore, the enhancements in TEC observed in the present investigations (see also Tsurutani et al., 2005; Zhang and Xiao, 2005) are related to the ionospheric electron density changes as a result of the additional ionization, due to the solar flare extreme EUV. Recently, Liu (2004, 2006) have investigated solar flare signatures of the ionospheric GPS total electron content and have reported that the maximum value of the TEC increase solely depends on the flare class, while the maximum rate of TEC change is related to not only the flare class but also to the time rate of change in the flare radiations. It appears that the GPS/TEC observations, which are due to the line-of-sight ultra high frequency propagation between a satellite and ground-based receiver, just reflect the electron density enhancements in the ionospheric region following an intense solar flare.

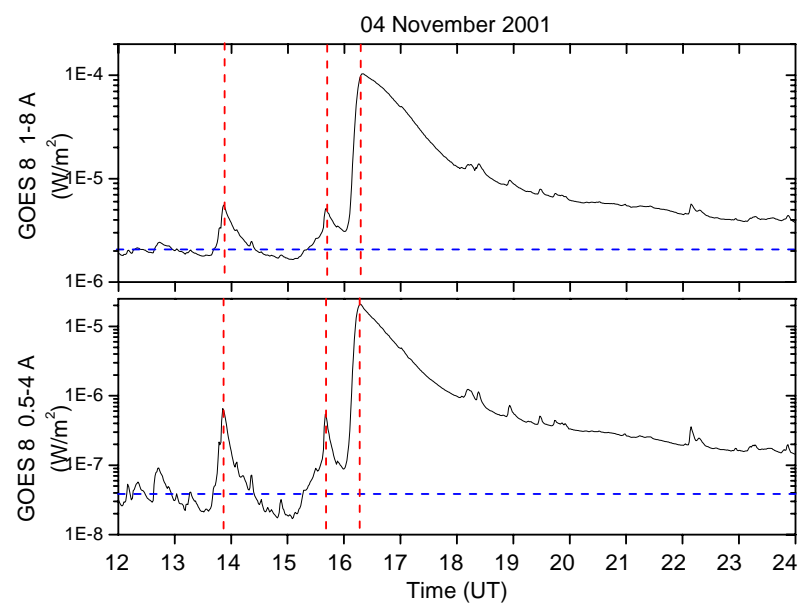

Fig. 6. Shows X-ray flux (1-8 A and 0.5-4 A) observed on 4 November 2001 by the satellite GEOS 12 from 12:00 UT to 24:00 UT. The blue horizontal line indicates the quiescent X-ray flux. The red vertical lines indicate the peaks in solar flare X-ray flux.

On the other hand, the ionospheric sounding using short and medium radio waves $(1-20 \mathrm{MHz})$ depends on the reflection on these waves from the ionospheric region to generate ionograms. As discussed by Mitra (1952), a sudden and intense increase in the ionization in the ionosphere is found to occur simultaneously with solar flares, resulting in the extreme cases in a complete fade out of radio signals over the Sun-lit region. As presented earlier X-ray flares are responsible for the enhanced ionization in the D-layer, resulting in the absorption of radio waves used for ionospheric sounding.

Figures 6 and 7 show another event of total + partial absorption of the ionospheric sounding frequencies on 4 November 2001 observed at SJC (at that time the ionospheric sounding at PAL was not in operation) during a less intense solar flare (X-1.0). During this solar flare no ionograms were obtained during the period 16:15 UT to $16: 55$ (forty minutes) and the duration for total + partial absorption of radio waves was about $3 \mathrm{~h}$. Figure 6 shows X-ray flux (1-8 A and $0.5-$ 4 A) observed on 4 November by the satellite GEOS 12 from 12:00 UT to 24:00 UT. Figure 7 shows 4 sets of ionograms obtained on 3 (black; normal day) and 4 November (red; day with solar flare) at SJC. Figure 7 shows examples of partial radio-wave absorption at 15:55, 17:00 and 18:00 UT and total radio-wave absorption at 16:15 UT observed at SJC.

The present investigations indicate that although the sudden enhancements in GPS/TEC lasted for about three hours, the radio fade out, as indicated by the ionospheric soundings, lasted for more than six hours. The absence of radiocommunication/transmission for such a long period must have resulted in enormous difficulties to various operating agencies. It is hoped that in a future investigation more case studies that are similar will be undertaken. This will be of immense importance for the present interest in space weather studies. 


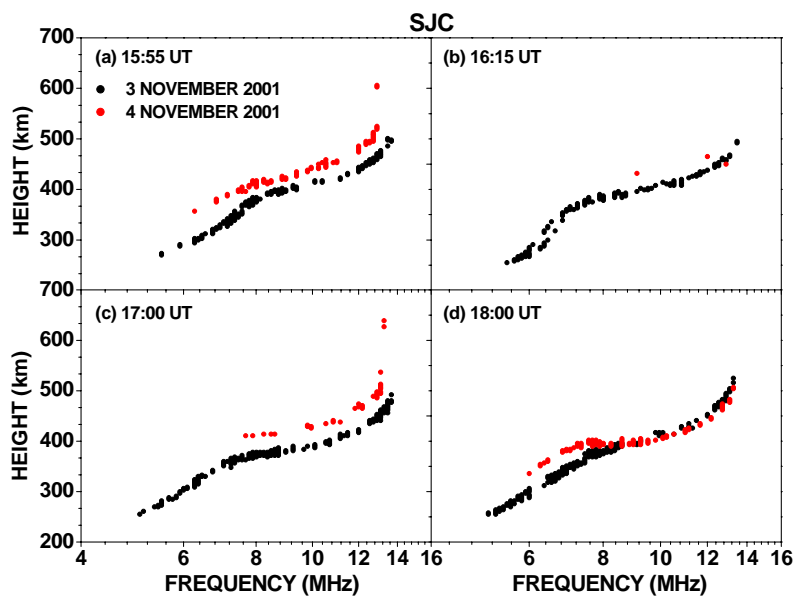

Fig. 7. The ionograms obtained at (a) 15:55 UT, (b) 16:15 UT, (c) 17:00 UT and (d) 18:00 UT on 3 November 2001 (normal day; black dots) and 4 November 2001 (solar flare day; red dots) at SJC. This period covers the ionograms obtained with partial radio-wave absorption at 15:55, 17:00, and 18:00 UT and complete absorption at 16:15 UT.

\section{Conclusions}

In this paper, we have presented and discussed the ionospheric sounding and GPS observations carried out at several stations in the equatorial and low-latitude regions in Brazil following the intense solar flare on 28 October 2003. The principal results of the investigations are summarized below:

1. The GPS observations at four stations (Table 1) show sudden TEC enhancements of about 25 TECU, lasting for about three hours, during the intense solar flare.

2. It appears that during intense solar flares extreme ultraviolet radiation can penetrate into the ionosphere, causing an increase in ionization and resulting in GPS/TEC enhancements of about 25 TECU for about $3 \mathrm{~h}$.

3. The ionospheric sounding observations at PAL and SJC show a lack of complete ionograms (total + partial radio wave absorption) for more than six hours. At PAL the period of total absorption was $45 \mathrm{~min}$, whereas at SJC the period of total absorption was $65 \mathrm{~min}$.

4. The total + partial radio fade out for more than six hours in the Brazilian sector, due to unusual enhancements in the solar flare X-ray radiation must have resulted in enormous difficulties to the radio station operating agencies using ionospheric radio transmissions.

5. Another less intense solar flare on 4 November 2001 exhibited similar characteristics of radio-wave absorption to that observed on 28 October.
Acknowledgements. Thanks are due to P. Wilkinson and J. W. Wright for several helpful comments. We would also like to convey our thanks to the authorities of the "Rede Brasileira de Monitoramento Continuo (RBMC) de GPS" for kindly allowing us to use the GPS data obtained by RBMC. This work was partially supported by grants from CNPq and FAPESP, Brazil.

Topical Editor M. Pinnock thanks two anonymous referees for their help in evaluating this paper.

\section{References}

Davies, K.: Ionospheric Radio, IEE Electromagnetic Waves Series 31, Short Run Press Ltd., Exeter, UK, 313-315, 1990.

Grant, I. F., MacDougall, J. W., Ruohoniemi, J. M., Bristow, W. A., Sofko, G. J., Koehler, J. A., Danskin, D., and Andre, D.: Comparison of plasma flow velocities determined by the ionosonde Doppler drift technique, SuperDARN radars, and patch motion, Radio Sci., 30, 1537-1549, 1995.

Hargreaves, J. K.: The solar-terrestrial envirronment, Cambridge Atmospheric and Space Science Series 5, Cambridge University Press, Cambridge, UK, 261-263, 1992.

Kelley, M. C., Makela, J. J., and de la Beaujardiere, O.: Convective ionospheric storms: A major space weather problem, Space Weather, 4, S02C04, doi:10.1029/2005SW000145, 2006.

Liu, J. Y., Lin. C. H., Tsai, H. F., and Liou, Y. A.: Ionospheric solar flare effects monitored by the ground-based GPS receivers: Theory and Observation, J. Geophys. Res., 109, A01037, doi:10.1029/2003JA009931, 2004.

Liu, J. Y., Lin. C. H., Chen, Y. I., Lin, Y. C., Fang, T. W., Chen, C. H., Chen, Y. C., and Hwang, J. J.: Solar flare signatures of the Ionospheric GPS total electron content, J. Geophys. Res., 111, A05308, doi:10.1029/2005JA011306, 2006.

Mitra, S. K.: The Upper Atmosphere, The Asiatic Society Monograph Series Volume 5, Calcutta, India, p. 325, 1952.

Mitra, A. P.: Ionospheric Effects of Solar Flares, Astrophysics and Space Science Library, D. Reidel Pubishing Company, Dordrecht-Holland, 1974.

Papagiannis, M. D.: Space Physics and Space Astronomy, Gordon and Breach Science Publishers, London, UK, 183-184, 1972.

Schunk, R. W. and Sojka, J. J.: Ionosphere-thermosphere space weather issues, J. Atmos. Terr. Phys., 58, 1527-1574, 1996.

Tsurutani, B. T., Judge, D. L., Guarnieri, F. L., Gangopadhyay, P., Jones, A. R., Nuttall, J., Zambon, G. A., Didkovsky, L., Mannucci, A. J., Iijima, B., Meier, R. R., Immel, T. J., Woods, T. N., Prasad, S., Floyd, L., Huba, J., Solomon, S. C., Straus, P., and Viereck, R.: The October 28, 2003 extreme EUV solar flare and resultant extreme Ionospheric effects: Comparison to other Halloween events and the Bastille Day event, Geophys. Res., Lett., 32, L03S09, doi:10.1029/2004GL021475, 2005.

Zhang, D. H. and Xiao, Z.: Study of ionospheric response to the 4B flare on 28 October 2003 using International GPS Service network data, J. Geophys. Res., 110, A03307, doi:10.1029/2004JA010738, 2005. 